\title{
BIOSYNTHESIS OF ZnO NANOPARTICLES USING OCIMUM BASILICUM AND DETERMINATION OF ITS ANTIMICROBIAL ACTIVITY
}

\author{
S. $\operatorname{Irshad}^{1}$, M. Riaz ${ }^{1}$, A. A. Anjum², S. Sana ${ }^{2}$, R. S. Z. Saleem ${ }^{3}$ and A. Shaukat ${ }^{1}$ \\ ${ }^{1}$ Department of Chemistry, Government Postgraduate College for Women Gulberg, Affiliated with Lahore College \\ University Lahore, Pakistan; ${ }^{2}$ Department of Microbiology, University of Veterinary and Animal Sciences, Lahore, \\ Pakistan; ${ }^{3}$ Department of Chemistry, SBASSE Lahore University of Management Sciences, Lahore, Pakistan \\ Corresponding Author E-mail address: shaguftairshad16@gmail.com
}

https://doi.org/10.36899/JAPS.2020.1.0021

Published online January 02, 2020

\begin{abstract}
Plant mediated $\mathrm{ZnO}$ nanoparticles has now become prominent among other metal oxide nanoparticles as easy to synthesize, cheap and safe method with multiple applications. In present study $10 \%$ extract of Ocimum basilicum was used as reducing and capping agent for the synthesis of $\mathrm{ZnO}$ nanoparticles with $230 \mathrm{~mL}$ of $0.2 \mathrm{M}$ Zinc Acetate dihydrate at room temperature $\left(25^{\circ} \mathrm{C}\right)$. The synthesized $\mathrm{ZnO}$ nanoparticles were dried at $60^{\circ} \mathrm{C}$, calcined at $100^{\circ} \mathrm{C}$ in oven and finally nanoparticles of weight $10.67 \mathrm{~g} / 100 \mathrm{~mL}$ of plant extract were weighed. Phytochemical analysis and FTIR characterization of plant extract and $\mathrm{ZnO}$ nanoparticles depicted strong presence of important bioactive components in plant extract while weak presence or absence was observed in $\mathrm{ZnO}$ nanoparticles supernatant layer. Nanoparticles IRspectrum showed two prominent sharp peaks at 660.33 and $560.22 \mathrm{~cm}^{-1}$ of $\mathrm{C}$ - alkyl chloride and hexagonal $\mathrm{ZnO}$ that was totally absent in crude extract spectrum. Further XRD diffractogram illustrated highly crystalline face centered cubic $\mathrm{ZnO}$ nanoparticles structure having hexagonal wurtzite geometry with average size $30-40 \mathrm{~nm}$. Moreover, microbicidal activity of synthesized nanoparticles $(100 \mathrm{mg} / \mathrm{mL})$ was measured against pathogenic strains and zones of inhibition against Staphylococcus aureus, Escherichia coli and Aspergillus niger were recorded as $1.05 \mathrm{~mm} \pm 0.137$, $36.15 \mathrm{~mm} \pm 0.304$ and $24.10 \mathrm{~mm} \pm 0.05$, respectively. Minimum inhibitory concentration for S. aureus and E. coli was calculated same as $312.5 \mu \mathrm{g} \pm 0.00$ whereas for Aspergillus niger was $5000 \mu \mathrm{g} \pm 0.00$. Thus a cheap and ecofriendly plant mediated complete method was developed that can be exploited on large scale synthesis to save the capita of Pakistan used to import antimicrobial drugs.
\end{abstract}

Key words: Ocimum basilicum; $\mathrm{ZnO}$ nanoparticles; antimicrobial activity; hexagonal wurtzite; zinc acetate dehydrate.

\section{INTRODUCTION}

Nanotechnology is emerging recently as new field of science that includes other basic disciplines such as biology, chemistry, physics and engineering work at nano scale level to create nano materials (Vaidyanathan et al. 2009). Whereas in nanobiotechnology, nano system is manufactured by utilizing biological materials and has enormous applications in life sciences. The nano system comprise of nano particles (NPs) with 1 to $100 \mathrm{~nm}$ size that increased its surface area for action and showed considerable benefits in agriculture, bio- engineering, electronics, automobiles pharmaceutics and cosmetics. These NPs showed exclusive optical, electrical, thermal, catalytic and antimicrobial properties (Parameswari, 2010). Various physical and chemical methods were used to manufacture metal nano particles. However, these methods have short comings; as they are more time consuming, use of toxic and non- biodegradable chemicals that are dangerous for biological systems. Therefore, plant mediated synthesis has got prominent position for NPs synthesis as it is inexpensive, nontoxic and eco- friendly alternative (Nadagouda and Varma, 2008).

Medicinal Plant extracts have bioactive constituents used in pharmaceutical formulations and are involved in reducing and capping of metal ions for the synthesis of NPs. Noble metals like Au and Ag NPs have been most extensively studied in past years with applications in biological system (Rajeshkumar et al. 2012; Sundrarajan et al. 2015). Little work is reported on the biosynthesis of some metals NPs like $\mathrm{MgO}, \mathrm{TiO}_{2}$, $\mathrm{CuO}, \mathrm{FeO}_{2}, \mathrm{Al}_{2} \mathrm{O}_{3}$ and $\mathrm{ZnO}$ (Moritz and Geszka-Moritz, 2013). From all these, $\mathrm{ZnO}$ NPs has got great attention in recent years with enormous applications as these are easy to synthesize, cheap and safe method (Pulit-prociak et al. 2016). Moreover, US FDA (United State Food and Drug Administration) recommended $\mathrm{ZnO}$ as (GRAS) which means generally recognized as safe (Sangani et al. 2015). It is widely used in biomedicine with enormous applications like drug delivery, anti- diabetic, anti- cancer and agricultural properties (Wodka et al. 2010). It has been widely used in cosmetic due to UV filtering 
properties especially in Sunblock lotions (Malapermal et al. 2015).

During this study medicinally famous herbal plant; Ocimum basilicum commonly known as Niazbo was used to prepare $\mathrm{ZnO}$ NPs. The plant bioactive phytochemicals have various health benefits and having natural antioxidant properties accomplished of neutralizing free radicals and reducing the brutality of diabetic, micro and macro vascular complications (Tejaswi et al. 2013). The extract of this plant was prepared to synthesize ZnO NPs that were characterized by FTIR, XRD and screened for antimicrobial activity.

\section{MATERIALS AND METHODS}

The plant material was collected from the garden of Govt. Post graduate College Gulberg, Lahore, Pakistan, identified and authenticated by Dr. Zaheer Uddin Khan; distinguish Prof. of Botany Govt. College University, Lahore. Voucher \#GC. Herb. Bot. 3409. The fresh plant was washed with distilled water several times to remove dirt particles, dried under shade for 6 days and grinded sample was stored in air tight jars for further investigations.

Synthesis of ZnO NPs: Plant extract (shoot, leaves and flower) was prepared by following Ahmed et al. (2016) with some modifications as; $10 \mathrm{gm}$ of dried plant material in $100 \mathrm{~mL}$ deionized water was heated for 2 hours at $80^{\circ} \mathrm{C}$ with continuous stirring and cooled at room temperature $\left(25^{\circ} \mathrm{C}\right)$. A clear extract was obtained after centrifugation at $4000 \mathrm{rpm}$ for 10 minutes. Further $\mathrm{ZnO}$ NPs were synthesized by following methodology of Senthilkumar and Sivakumar (2014) with some modification. Zinc acetate dihydrate $(0.2 \mathrm{M})$ was freshly prepared in deionized distilled water and $230 \mathrm{~mL}$ was added to $100 \mathrm{~mL}$ of plant extract at room temperature $\left(25^{\circ} \mathrm{C}\right)$. Brown $\mathrm{ZnO}$ NPs were instantly appeared that thickened within minutes and the reacted solution was dried at $60^{\circ} \mathrm{C}$ for 24 hours. The dried crystals were further calcined at $100^{\circ} \mathrm{C}$ for 1 hour, cooled, weighed and stored in brown bottles for future investigations. Freshly prepared $100 \mathrm{~mL}$ leaf extract was also dried at $60^{\circ} \mathrm{C}$ for 24 hours for phytochemical characterization.

Characterization: Bioactive phytochemicals like alkaloids, tannins, phenols, flavonoids, carbohydrates, proteins, terpenes and saponins were qualitatively tested in plant extract and $\mathrm{ZnO}$ NPs supernatant layer to observe their strong/ weak presence or absence by using important reported tests (Tiwari et al. 2011). Identification chemical bonds of functional groups in dried plant extract and ZnO NPs by FTIR was performed at Department of applied Chemistry, PCSIR, Lahore, Pakistan (Moghaddam et al. 2017). Further XRD studies were taken in the Department of Chemistry, SBASSE,
Lahore University of Management Sciences, Lahore, Pakistan (Santhoshkumar et al. 2017).

Antimicrobial studies: The synthesized ZnO NPs were evaluated for antimicrobial activity; well diffusion method (Hasan et al. 2009) was applied. For antibacterial assay, the refresh day old culture of Staphylococcus aureus (S. aureus) and Escherichia coli (E. coli) were uniformly spread over nutrient agar plates having wells of $4 \mathrm{~mm}$. ZnO NPs $(100 \mathrm{mg} / \mathrm{mL})$ normal solution was introduced in the wells under sterilized conditions and incubated at $37^{\circ} \mathrm{C}$ for 24 hours. The zone of inhibition $(\mathrm{mm})$ around well was measured; same procedure was applied for pathogenic fungus: Aspergillus niger ( $A$. niger) during antifungal assay. All the bacterial and fungal strains used in this study were obtained from the Department of Microbiology, University of Veterinary and Animal Sciences, Lahore. Gentamycin $(100 \mathrm{mg} / \mathrm{mL})$ was used as standard antibiotic against bacterial strains and zone of inhibition ( $\mathrm{mm}$ ) was measured.

Minimum Inhibitory Concentration: Minimum Inhibitory Concentration (MIC) was measured by following well diffusion method in replicates $(\mathrm{N}=3)$ for each microbial strain. This standard method for antimicrobial assay (Wiegand et al. 2008) was employed in tube serial dilutions of $\mathrm{ZnO}$ NPs $(100 \mathrm{mg} / \mathrm{mL})$ in bacterial and fungal growth media. The pathogenic microbes were incubated at $37^{\circ} \mathrm{C}$ for 24 hours and lowest inhibitory concentration was scored. All the experiments were applied in replicates $(\mathrm{N}=3)$ to apply descriptive analysis on SPSS statistics 17.0 to calculate Mean value with standard deviation (SD).

\section{RESULTS AND DISCUSSION}

The plant mediated method of $\mathrm{ZnO}$ NPs synthesis is a recent approach that is the elucidation of a cheap, eco-friendly and scale up synthetic method. Medically important plants have such phytochemicals which act to stabilize and reduce metal oxides for the synthesis of NPs with controlled shape and size (Agarwal et al. 2017). Further such famous phytochemicals are reported to involve inhibitory growth mechanism in pathogenic microbial strains (Zhang et al. 2008). Hence, such plant mediated NPs free from toxins can have vast scope in the field of biomedical science, food and cosmetics industries, consequently this study now become a foremost research area for researchers. Keeping this in mind a medically renowned plant Ocimum basilicum commonly known as "Niazbo" was selected and identified. Further $230 \mathrm{~mL}$ of $0.2 \mathrm{M}$ solution of Zinc acetate dihydrate was poured in $100 \mathrm{~mL}$ of fresh plant extract at room temperature $\left(25^{\circ} \mathrm{C}\right)$ and brown $\mathrm{ZnO}$ nanoparticles were instantly appeared that grew larger within seconds and finally settled down leaving supernatant layer which was also taken for phytochemical 
investigation. The visual diagram of all the procedure in the form of flow sheet was presented in fig. 1. Further the produced NPs were dried at $60^{\circ} \mathrm{C}$ in oven for 24 hours and dried brown $\mathrm{ZnO}$ NPs were obtained. Moreover, NPs were calcined at $100^{\circ} \mathrm{C}$ for 1 hour. Thus green synthesized $\mathrm{ZnO}$ NPs were weighed as $10.67 \mathrm{~g} / 100 \mathrm{~mL}$ of plant extract. This is the first-time reported concentration of Ocimum basilicum $\mathrm{ZnO}$ NPs with complete scheme of work.

Characterization: Well-known qualitative tests were performed to determine the presence or absence of important bioactive compounds like alkaloids, flavonoids, carbohydrates, proteins, terpenes, phenols and saponins; in the crude leaves extract and in supernatant layer after $\mathrm{ZnO}$ NPs settlement. There was strong presence of all above bioactive phytochemicals in leave extract whereas weak presence of most phytochemicals was noticed in supernatant layer. During screening proteins and phenols were absent in supernatant layer, although saponins were strongly present in both extracts. The weak presence or absence of these natural products was in agreement with reported literature of Malapermal et al. (2015) that bioactive constituents are involved in reduction and capping of metal oxides during NPs synthesis. Tejaswi et al. (2013) documented triterpenes, eugenol and flavonoids as important ingredients in plant extracts responsible for the formation of silver NPs. Absence of protein might be related with its association with ZnO NPs synthesis and stabilization (Nalvolthula et al. 2014).

FTIR analysis: Further FTIR of crude leaves extract and $\mathrm{ZnO}$ NPs also depicted the compatible results with other researchers' findings and different pattern of peaks were observed in both dried moieties as shown in fig. 2 .

There is a broad stretch between $3000-3500 \mathrm{~cm}^{-}$ ${ }^{1}$ with absorption maxima at $3337.88 \mathrm{~cm}^{-1}$ that ascribed the stretching frequencies of amino and hydroxyl of amine, alcohols and phenols. A weak absorption peak at $2926.32 \mathrm{~cm}^{-1}$ represented the symmetric and asymmetric stretching of aliphatic functional group $\left(\mathrm{CH}_{3}\right.$ and $\left.\mathrm{CH}_{2}\right)$. When these two peaks are compared with the IRspectrum of $\mathrm{ZnO}$ NPs, these stretching became narrow with decrease of peak broadening in NPs spectrum and absorption maxima is shifted to $3160.45 \mathrm{~cm}^{-1}$, might be associated that these functional groups are used to reduce $\mathrm{Zn}^{+2}$. Further by comparing both spectrums, visible difference between absorption maxima and stretching frequencies were found. As $\mathrm{ZnO}$ NPs spectrum has two prominent sharp peaks at 660.33 and $560.22 \mathrm{~cm}^{-1}$ of Calkyl chloride and hexagonal $\mathrm{ZnO}$ (Salem et al. 2016) that is totally absent in crude plant extract spectrum. Moreover, peak at $1584.32 \mathrm{~cm}^{-1}$ (carbonyl functional group in amide I and II) and two peaks at $1393.76 \mathrm{~cm}^{-1}$; $1264.2 \mathrm{~cm}^{-1}$ (C-N stretching frequencies of amide I and $\mathrm{CH}_{2-}$ scissoring vibrations of proteins) reducibly appeared with absorption maxima at 1570.25 and $1412.34 \mathrm{~cm}^{-1}$ in NPs spectrum. These results are also in agreement with reported findings that proteins stabilize the NPs and also a justification of protein absence during the phytochemical analysis in supernatant layer of $\mathrm{ZnO}$ NPs. A prominent peak at $1051.29 \mathrm{~cm}^{-1}$ and a weak peak at $865 \mathrm{~cm}^{-1}$ corresponded to $\mathrm{C}-\mathrm{O}$ vibrational stretching frequencies of alcohol and amino acids (Moghaddam et al. 2017) and C-N stretch of amine respectively found in crude leave spectrum whereas two reduced weak peaks appeared at $1020.65 \mathrm{~cm}^{-1}$ and $958.43 \mathrm{~cm}^{-1}$ in $\mathrm{ZnO} \mathrm{NPs}$ spectrum. The presence of some sharp and prominent peaks in crude extract spectrum and absence or weak presence in $\mathrm{ZnO}$ NPs spectrum suggested that those functional groups of active ingredients were performing the job of capping, dispersing and stabilizing agents for NPs. Wonsawat, 2014 found during research study that Basil leaves extract contained active reducing agents those reduce metal ions into metal NPs.

XRD studies: The diffractogram of plant mediate $\mathrm{ZnO}$ NPs given in fig. 3 had noticeable prominent peaks appeared between $2 \theta$ (degree) against intensity. The prominent indices plane of $\mathrm{ZnO}$ (hkl) calculated as (100), (002), (101), (102), 110), (103) and (112) corresponding to diffraction angles of $32.2^{\circ}, 34.21^{\circ}, 36.31^{\circ}, 45.87^{\circ}$, $52.10^{\circ}, 60.52^{\circ}$ and $66.98^{\circ}$ indexed the size of crystals. The average size of crystals was between $30-40 \mathrm{~nm}$ estimated by Debye-Scherrer equation (Santhoshkumar et al. 2017). Moreover, the spectrum was in agreement with documented diffraction data card (JCPDS-36-1451) and also fairly comparable with reported literature of other researchers (Irshad et al. 2018). Further Bragg Equation (Senthilkumar and Sivakumar, 2014) was used to calculate crystal structure that was found highly crystalline face centered cubic having hexagonal wurtzite geometry. The similar results were also reported by Vennila et al. (2016).

Antimicrobial activity: The microbicidal activity of synthesized NPs $(100 \mathrm{mg} / \mathrm{mL})$ was measured against pathogenic strains as shown in fig. 4 and found $31.05 \mathrm{~mm} \pm 0.137$ zone of inhibition against $S$. aureus, $36.15 \mathrm{~mm} \pm 0.304$ for $E$. coli and $24.10 \mathrm{~mm} \pm 0.05$ for $A$. niger given in the table. These results documented better antibacterial activity of produced $\mathrm{ZnO}$ NPs than the standard antibiotic; Gentamycin $(100 \mathrm{mg} / \mathrm{mL})$ that showed zone of inhibition $25 \mathrm{~mm}$ against $S$. aureus and $26 \mathrm{~mm}$ for $E$. coli. The biocidal action of $\mathrm{ZnO} \mathrm{NPs}$ revealed their mechanism that involved the disruption of cell membrane with the action of $\mathrm{Zn}^{+2}$ on its surface that ultimately cause the death of microbes (Gunalan et al. 2012).

Further standard protocols were followed to measure MIC for the above mentioned strains and observed concentrations are given in the table for $S$. aureus and $E$. coli were same of $312.5 \mu \mathrm{g} \pm 0.00$ and $A$. 
niger was $5000 \mu \mathrm{g} \pm 0.00$. This minimum concentration of $\mathrm{ZnO}$ NPs required for antimicrobial activity as given in the table depicted the cost effectiveness of initially green synthesized ZnO NPs $(10.67 \mathrm{~g} / 100 \mathrm{~mL})$ and its application in antimicrobial activity. Some researchers also studied mode of inhibitory action of ZnO NPs for microbial growth, as Mishra and Sharma (2015) documented cell damage caused by these NPs with the presence of protein and nucleic acid of nutrient agar, Femi et al. (2011) demonstrated the surface binding of NPs with thiol group of glycoproteins one the cell wall of microbes and decreases the permeability with subsequently lyses of cell to inhibit cell growth (Hasan et al. 2009). Gunalan et al. (2012) also explained the damage of cell membrane with leakage of protein, minerals and genetic material by the interaction of $\mathrm{ZnO}$ NPs with microbial strains.

Rout et al. (2012) measured zone of inhibition (mm) of Ocimum sanctum silver NPs against E. coli, $S$. aureus and $A$. niger as; $14 \pm 0.33,19 \pm 1.30$ and $12.24 \pm 0.03$ respectively. Sivaranjani and Meenakshisundaram, (2013) synthesized silver NPs using Ocimum basilicum leaves extract and estimated $11 \mathrm{~mm}$ zone of inhibition against Pseudomonas aereginose however no zone was observed for E. coli and Bacillus subtilis. Singhal et al. (2011) calculated MIC of silver NPs 0.314 and 1.25 $\mathrm{mg} / \mathrm{mL}$ for $E$. coli and $S$. aureus respectively. During this present study Ocimum basilicum ZnO NPs depicted better antimicrobial activity than other researchers' findings and with low MIC.
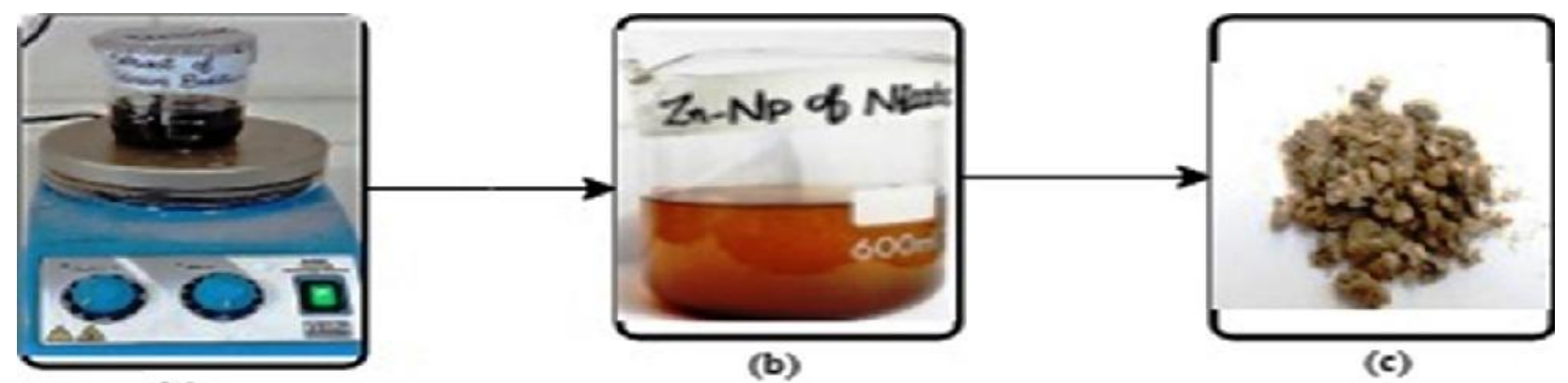

(a)

Figure 1. Visual diagram of Ocimum basilicum ZnO NPs biosynthesis; (a) plant extract preparation (b) synthesis of ZnO NPs (c) dried and calcined ZnO NPs.

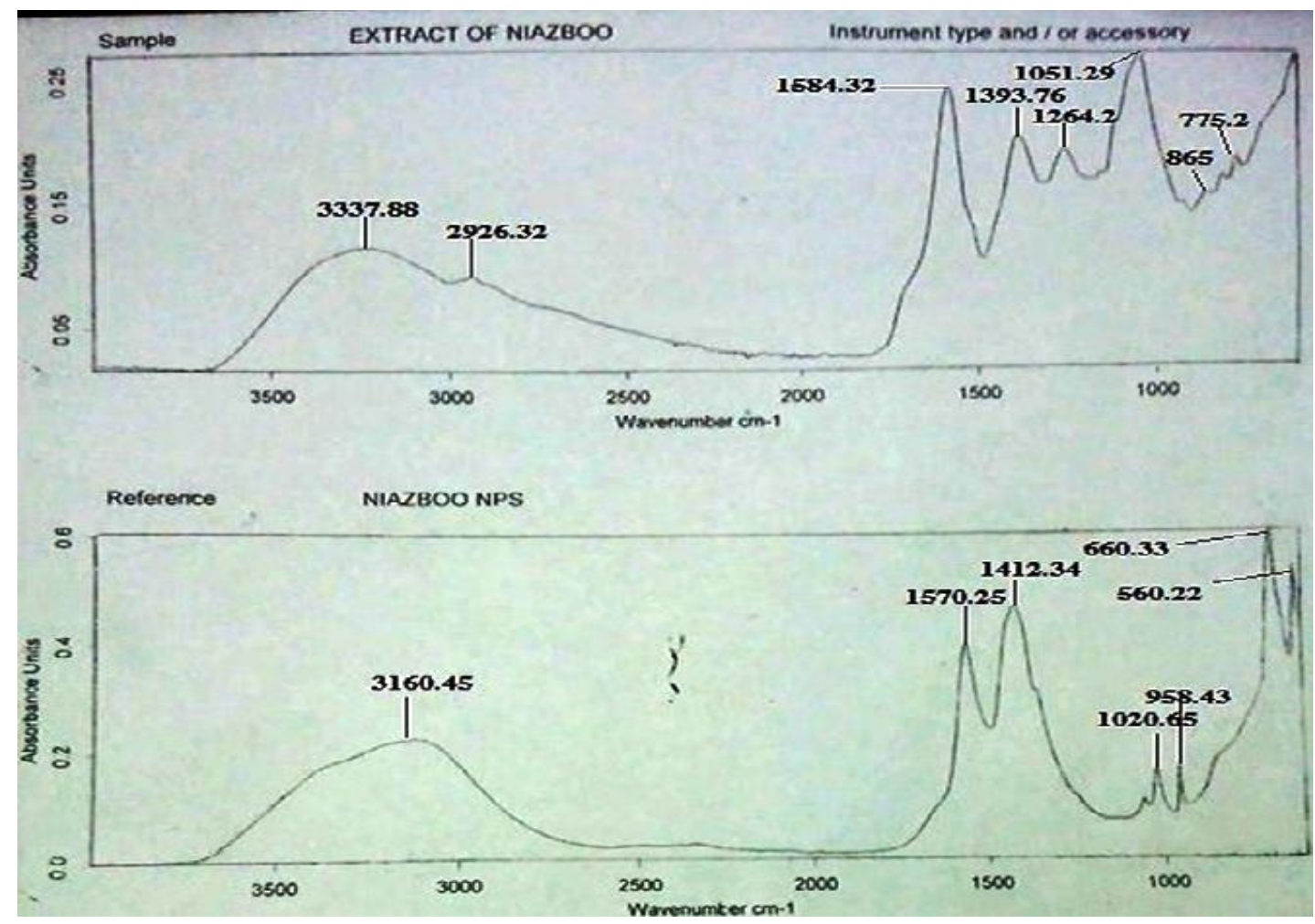


Figure 2. FTIR of crude dried leaves extract and its ZnO NPs representing characteristic functional groups peaks.

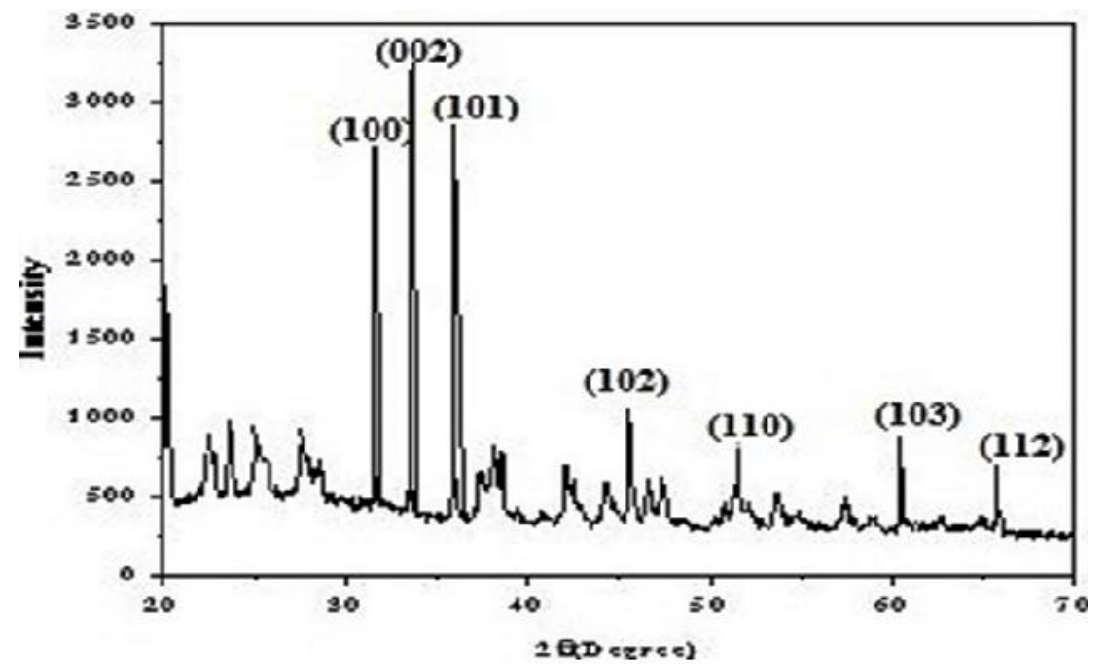

Figure 3. XRD diffractogram of Ocimum basilicum ZnO NPs.

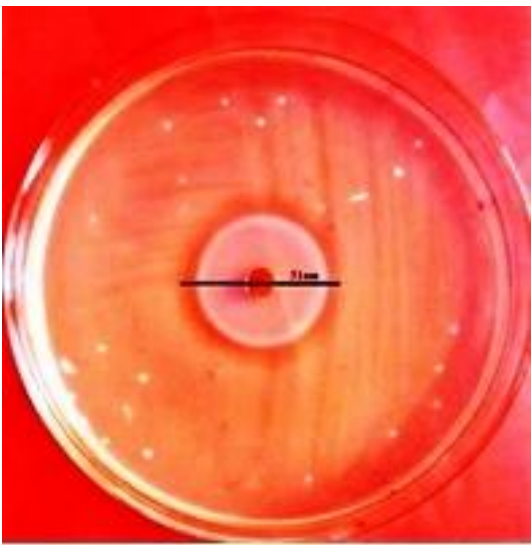

A

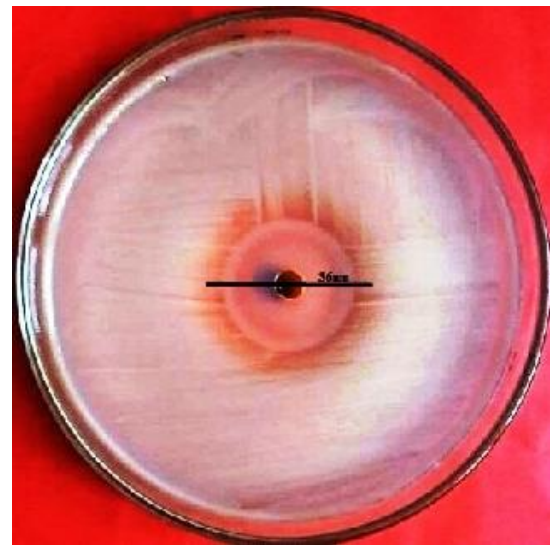

B

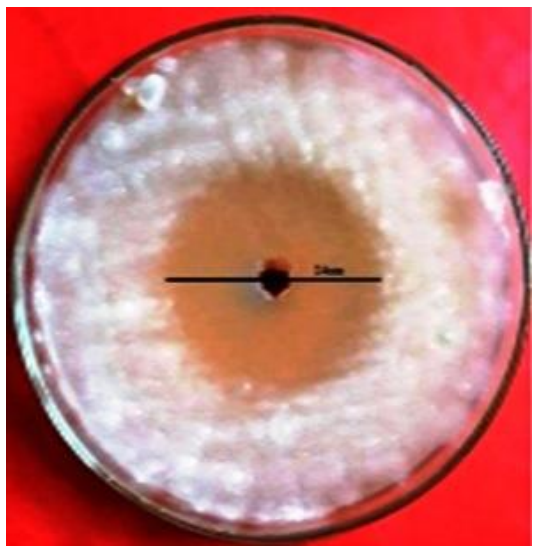

C

Figure 4. Zone of inhibition measured for antimicrobial activity of Ocimum basilicum ZnO NPs evaluated on (a) S. aureus (b) E. coli (c) A. niger

Table. Determination of zone of inhibition measured by Well Diffusion Method and MIC of Ocimum basilicum ZnO NPs against pathogenic microbial strains

\begin{tabular}{|c|c|c|c|c|}
\hline $\begin{array}{c}\text { Microbial } \\
\text { strain }\end{array}$ & $\begin{array}{c}\text { Aq. Extract of Ocimum } \\
\text { basilicum leaves } \\
(100 \mathrm{mg} / \mathrm{mL})\end{array}$ & $\begin{array}{c}\text { ZnO NPs of Ocimum } \\
\text { basilicum leave } \\
(100 \mathrm{mg} / \mathrm{mL}) \pm \mathrm{SD} \\
\end{array}$ & $\begin{array}{c}\text { Gentamycin } \\
\text { (Std. Antibiotic) } \\
(100 \mathrm{mg} / \mathrm{mL}) \\
\end{array}$ & $\mathrm{MIC} \pm \mathrm{SD}$ \\
\hline S. aureus & No zone & $31.05 \mathrm{~mm} \pm 0.137$ & $25 \mathrm{~mm}$ & $312.5 \mu \mathrm{g} \pm 0.00$ \\
\hline E. coli & No zone & $36.15 \mathrm{~mm} \pm 0.304$ & $26 \mathrm{~mm}$ & $312.5 \mu \mathrm{g} \pm 0.00$ \\
\hline A. niger & No zone & $24.10 \mathrm{~mm} \pm 0.05$ & ------- & $5000 \mu \mathrm{g} \pm 0.00$ \\
\hline
\end{tabular}

Where no. of treatments $(\mathrm{N})=3$, Standard deviation $=\mathrm{SD}$

Conclusion: $\mathrm{ZnO}$ nano particles were synthesized by using Ocimum basilicum plant extract that effectively inhibit pathogenic microbial strains of clinical source. Moreover, during characterization, FTIR of ZnO NPs documented clearly the capping, reducing and stabilizing phytochemicals found in crude extract of plant. XRD diffractogram revealed characteristic peak of $\mathrm{ZnO}$ NPs with size range $30-40 \mathrm{~nm}$.

\section{REFERENCES}


Agarwal, H., S.V. Kumar and S. RajeshKumar (2017). A review on green synthesis of $\mathrm{ZnO}$ Nps-An ecofriendly approach, Resour. efficient Technol. 3(4): 406- 413. doi: 10.1016/j.reffit.2017.03.002.

Ahmed, K., N. Ahmed, M.T. Siddiqui and A.A. Aziz (2016). Green synthesis of silver nano particles by plant leaf extract. Fuuast J. Biol. 6(1): 61-64.

Femi, V., P.H. Prabha, P. Sudha, B. Devibala and A.L. Jerald (2011). Anti-bacterial effect of. $\mathrm{ZnO}-\mathrm{Au}$ nanocomposites. Int. J. Biotechnol. Eng. 1(1), 18.

Gunalana, S., R. Sivaraja and V. Rajendran (2012). Green synthesized $\mathrm{ZnO}$ nanoparticles against bacterial and fungal pathogens, Prog. Nat. Sci. Mater. Int. 22(6): 693- 700 .

Hasan, M.F., R. Das, A. Khan, M.S. Hasan and M. Rahman (2009). The determination of antibacterial and antifungal activities of Polygonum hydropiper (L.) Root Extract. Adv. Biol. Res. 3(1-2): 53-56.

Irshad, S., A. Salamat, A.A. Anjum, S. Sana, R.S. Saleem, A. Naheed and A. Iqbal (2018). Green tea leaves mediated $\mathrm{ZnO}$ nanoparticles and its antimicrobial activity. Cogent Chem. 4(1): 1469207.

https://doi.org/10.1080/23312009.2018.1469207

Malapermal, V., J.N. Mbatha, R.M. Gengan, and K. Anand (2015). Biosynthesis of. bimetallic AuAg nanoparticles using Ocimum basilicum (L.) with an-. tidiabetic and antimicrobial properties. Adv. Mater. Lettre. 6(12): 1050- 1057.

Mishra V. and R. Sharma (2015). Green Synthesis of Zinc Oxide Nanoparticles Using Fresh Peels Extract of Punica granatum and its Antimicrobial Activities. Int. J. Pharma Res. Health Sci. 3(3): 694- 699.

Moghaddam, A.B., M. Moniri, S. Azizi et al. (2017). Biosynthesis of ZnO Nanoparticles by a New Pichia kudriavzevii Yeast Strain and Evaluation of Their Antimicrobial and Antioxidant Activities. Molecules. 22(6): 872- 890, doi:10.3390/molecules22060872.

Moritz, M. and M. Geszka-Moritz (2013). The newest achievements in synthesis, immobilization and practical applications of antibacterial nanoparticles. Chem. Engg. J. 228:596-613.

Nadagouda, M.N. and R.S. Varma (2008). Green synthesis of silver and palladium nanoparticles at room temperature using coffee and tea extract. Green Chem. 10(8): 859-862.

Nalvolthula, R., M.P. Pratap Rudra and R. Merugu (2014). Phytochemical analysis, synthesis, antitumor and antimicrobial activity of silver nanoparticles using flower extracts of Lxora coccinea. Int. J. ChemTech. Res. 7(5): 23742380 .

Parameswari, E. (2010). The bactericidal potential of silver nanoparticles. Int. Res. J. Biotechnol. 1(3): 044-049.

Pulit-prociak, J., J. Chwastowski, A. Kucharski and M. Banach (2016). Applied surface science functionalization of textiles with silver and zinc oxide nanoparticles, Appl. Surf. Sci. 385: 543553.

Rajeshkumar, S., C. Kannan and G. Annadurai (2012). Green synthesis of silver nanoparticles using marine brown algae Turbinaria conoides and its antibacterial activity. J. Pharm. Bio. Sci. 3(4): 502-510.

Rout, Y., S. Behera, A.K. Ojha and P.L. Nayak (2012). Green synthesis of silver nanoparticles using Ocimum sanctum (Tulashi) and study of their antibacterial and antifungal activities. J. Microbiol. Antimicrob. 4(6): 103-109.

Salem, N.M., L.S. Albanna, A.O. Abdeen, Q.I. Ibrahim and A.M. Awwad (2016). Sulfur Nanoparticles Improves Root and Shoot Growth of Tomato. J. Agri. Sci. 8(4): 179- 185.

Sangani, M.H., M.N. Moghaddam and M. Mahdi (2015). Inhibitory effect of zinc oxide nanoparticles on pseudomonas aeruginosa biofilm formation, Nanomed. J. 2(2): 121-128.

Santhoshkumar, J., S.V. Kumar and S. Rajeshkumar (2017). Synthesis of zinc oxide nanoparticles using plant leaf extract against urinary tract infection pathogen, Resour. Efficient Technol. 3(4): 1-7 doi.org/10.1016/j.reffit.2017.05.001.

Senthilkumar, S.R. and T. Sivakumar (2014). Green tea (Camellia sinensis) mediated synthesis of zinc oxide $(\mathrm{ZnO})$ nanoparticles and studies on their antimicrobial activities, Int. J. Pharm.Pharma. Sci. 6(6): 461- 465 .

Singhal, G., R. Bhavesh, K. Kasariya, A.R. Sharma and R.P. Singh (2011). Biosynthesis of silver nanoparticles using Ocimum Sanctum (Tulsi) Leaf extract and screening its antimicrobial activity. J. Nanopart. Res. 13: 2981- 2988.

Sivaranjani, M. and K. Meenakshisundaram (2013). Biological synthesis of silver nanoparticles using Ocimum basilicum leaf extract and their antimicrobial activity. Int. Res. J. Pharm. 4(1): 225- 229.

Sundrarajan, M., S. Ambika and K. Bharathi (2015). Plant-extract mediated synthesis of $\mathrm{ZnO}$ nanoparticles using Pongamia pinnata and their activity against pathogenic bacteria, Adv. Powder Technol. 26: 1294-1299.

Tejaswi, T., K.V. Rao and C.S. Chakara (2013). Sliver nanoparticles synthesis and stabilization by different species of ocimum and characterization 
for its antimicrobial activity. Int. J. Curr. Eng. Tech. 3(2): 501-506.

Tiwari, P., B. kumar, M. Kaur, G. Kaur and H. Kaur (2011). Phytochemical screening and extraction: A review. Int. Pharma. Sci. 1(1): 98- 106.

Vaidyanathan, R., K. Kalishwaralal, S. Gopalram and S. Gurunathan (2009). Retracted: Nanosilver- The burgeoning therapeutic molecule and its green synthesis. Biotechnol. Adv. 27(6): 924-937.

Vennila, S., S.S. Jesurani, M. Priyadharshini and M. Ranjani (2016). Eco-friendly synthesis of metal oxide nanoparticles using Carissa carandas fruit extract. World J. Pharma. Res. 5(7): 806- 812.

Wiegand, I., K. Hilpert and R.E.W. Hancock (2008). Agar and broth dilution methods to determine the minimal inhibitory concentration (MIC) of antimicrobial substances. Nat Protoc. 3(2): 163175.

Wodka, D., E. Bielaníska, R. P. Socha, M. ElzbieciakWodka, J. Gurgul, P. Nowak et al. (2010). Photocatalytic activity of titanium dioxide modified by silver nanoparticles, ACS Appl. Mater. Interfaces. 2(7):1945-1953.

Wonsawat (2014). The Green Synthesis AgNPs from Basil Leaf Extract. Int. J. Chem. Mol. Eng. 8(5): 448- 450.

Zhang, L., Y. Ding, M. Povey and D. York (2008). ZnO nanofluids - A potential antibacterial agent. Prog. Nat. Sci. 18(8): 939- 944. 